\title{
Evaluation of the Short-Term Cost-Effectiveness of IDegLira Versus Continued Up-Titration of Insulin Glargine U100 in Patients with Type 2 Diabetes in the USA
}

Barnaby Hunt (D) Michelle Mocarski · William J. Valentine •

Jakob Langer

Received: January 23, 2017 / Published online: March 9, 2017

(c) The Author(s) 2017. This article is published with open access at Springerlink.com

\section{ABSTRACT}

Introduction: Effective glycemic control can reduce the risk of complications and their related costs in type 2 diabetes mellitus (T2DM). However, many patients fail to reach glycemic targets, often because of adverse effects of treatment (including hypoglycemia or weight gain). The present analysis evaluated the short-term cost-effectiveness of IDegLira versus continued up-titration of insulin glargine U100 in patients with T2DM failing to achieve glycemic control on basal insulin in the US setting. Methods: The cost per patient achieving treatment target (cost of control) was assessed for various single and composite endpoints for the entire trial population and in patients with baseline glycated hemoglobin (HbA1c) $>8.0 \%$ and $\mathrm{HbA} 1 \mathrm{c}>9.0 \%$. The proportions of patients achieving treatment targets were analyzed using

Enhanced content To view enhanced content for this article go to http://www.medengine.com/Redeem/ 0197F0606A34B061.

B. Hunt $(\varangle)$. W. J. Valentine

Ossian Health Economics and Communications,

Basel, Switzerland

e-mail: hunt@ossianconsulting.com

M. Mocarski

Novo Nordisk Inc., Plainsboro, NJ, USA

J. Langer

Novo Nordisk A/S, Søborg, Denmark data obtained in the DUAL V study. Costs were accounted based on published wholesale acquisition costs.

Results: When assessing the full trial population, IDegLira was associated with lower annual cost of control than continued up-titration of insulin glargine U100 for patients achieving HbA1c $\leq 6.5 \%$ without confirmed hypoglycemia (by $\$ 10,608$ ), HbA1c $\leq 6.5 \%$ without weight gain (by $\$ 29,215$ ), and HbA1c $\leq 6.5 \%$ without confirmed hypoglycemia and weight gain (by $\$ 57,351$ ). A similar pattern was observed when multifactorial treatment targets were based on achieving a glycemic target of $7.0 \%$. When only HbA1c was considered, IDegLira was associated with a lower cost per patient achieving HbA1c $\leq 6.5 \%$ (by $\$ 3306$ ) but cost of control was equivalent for a target of $\mathrm{HbA} 1 \mathrm{c}<7.0 \%$. In patients with baseline HbA1c $>8.0 \%$ and $\mathrm{HbA} 1 \mathrm{c}$ $>9.0 \%$, IDegLira was associated with a lower cost of control for all treatment targets.

Conclusion: The significantly greater clinical efficacy in terms of bringing patients to treatment targets identified in the DUAL V study results in lower cost of control values for IDegLira versus continued up-titration of insulin glargine U100 in the USA. This suggests IDegLira is a cost-effective treatment option in the USA.

Funding: Novo Nordisk A/S and Novo Nordisk Inc. 
Keywords: Cost; Endocrinology; IDegLira; Type 2 diabetes mellitus; USA

\section{INTRODUCTION}

In the USA, estimates suggest that the total cost of diagnosed diabetes mellitus in 2012 was $\$ 245$ billion, comprised of $\$ 176$ billion in direct medical costs and $\$ 69$ billion in lost productivity [1]. On a per patient level, estimates have suggested that a patient with type 2 diabetes (T2DM) will accrue direct medical costs of approximately $\$ 85,200$ over their lifetime, with costs increasing substantially in patients diagnosed at a younger age [2]. The majority of the total cost (48-64\% depending on age at diagnosis) is comprised of treatment of diabetes-related complications. These costs may be reduced by improving treatment for patients with T2DM.

Data from a number of large-scale studies and meta-analyses has shown that improving glycemic control, as measured by glycated hemoglobin (HbA1c), can reduce the incidence of micro- and macrovascular diabetes-related complications in patients with T2DM [3-9]. Therefore, maintaining glycemic control despite the progressive nature of the disease has formed the mainstay of treatment for patients with T2DM. However, data has also shown that patients benefit from a multifactorial approach to treatment where, as well as maintaining tight glycemic control, treatment aims to minimize the risk of hypoglycemia, control cardiovascular risk factors such as blood pressure, serum lipid levels, and reduce or control body weight $[10,11]$. Controlling these factors may also result in improved adherence to medications and therefore improved glycemic control.

Based on this evidence, the American Diabetes Association (ADA) has released treatment guidelines for a number of parameters. The key target of $\mathrm{HbA} 1 \mathrm{c}<7 \%$ is recommended for most patients, with a more stringent target of HbA1c $\leq 6.5 \%$ if this can be achieved without significant hypoglycemia or other adverse effects of treatment [12]. Recommendations also state that the effect of medications on body weight and hypoglycemia risk should be considered when making treatment decisions $[13,14]$.

In patients requiring basal insulin, doses can be titrated to maintain glycemic control. However, up-titration of basal insulin may result in weight gain and an increased risk of hypoglycemia $[15,16]$. IDegLira represents an alternative therapy for patients not adequately controlled on basal insulin. IDegLira is a fixed ratio combination of insulin degludec and the glucagon-like peptide-1 (GLP-1) receptor agonist liraglutide. The fixed-ratio combination was developed to take advantage of the combined effects of a basal insulin and a GLP-1 receptor agonist on glycemic control through their complementary mechanisms of action. Treatment with IDegLira has been shown to result in greater reductions in HbA1c and body weight, and a lower rate of hypoglycemic events than insulin glargine U100 [17].

The aim of the present analysis was to evaluate, in a simple and transparent analysis, the short-term cost-effectiveness of IDegLira versus continued up-titration of insulin glargine U100 in patients with T2DM failing to achieve glycemic control on basal insulin in the US setting. The analysis assessed the cost per patient achieving HbA1c-focussed and multifactorial (capturing weight gain and hypoglycemia) treatment targets. Insulin glargine U100 was considered the most appropriate comparator for the analysis as it is the most commonly prescribed basal insulin in the USA, up-titration of insulin glargine represents a potential treatment strategy for patients failing to achieve glycemic control, and there is published head-to-head trial evidence comparing the two therapies. While there are other treatment options for patients not achieving glycemic control on basal insulin, there are currently no head-to-head clinical trials comparing IDegLira with GLP-1 receptor agonists in combination with basal insulin (either fixed ratio or free combinations), and the DUAL VII trial comparing IDegLira with basal-bolus insulin will report in mid-2017. 


\section{METHODS}

\section{Clinical Data}

All clinical data used in the analysis were obtained from the DUAL V trial [17]. DUAL V was a 26-week, open-label study comparing the safety and efficacy of IDegLira and continued up-titration of insulin glargine U100 in patients with T2DM not achieving glycemic targets on insulin glargine U100. In total, 557 patients were randomly allocated to the two treatment arms in a 1:1 ratio. Confirmed hypoglycemia was defined as any episode requiring assistance of another person to actively administer carbohydrate, glucagon, or other resuscitative actions, or an episode biochemically confirmed by a plasma glucose value of $<3.1 \mathrm{mmol} / \mathrm{L}$ $(56 \mathrm{mg} / \mathrm{dL})$, with or without symptoms consistent with hypoglycemia. Three patient populations were included in the analysis: all patients included in the DUAL $\mathrm{V}$ trial, patients with HbA1c $>8.0 \%$ at baseline, and patients with HbA1c $>9.0 \%$ at baseline. These three populations were selected to reflect all patients with T2DM, and those who are furthest from achieving recommended treatment targets and therefore are at the highest risk of developing diabetes-related complications. In the USA, $55.2 \%$ of patients with type 2 diabetes receiving basal insulin have an HbA1c $\geq 8.0 \%$, and $33.1 \%$ have an $\mathrm{HbA1c} \geq 9.0 \%$ [18]. These patient subgroups also represent cutoffs applied by the Diabetes Recognition Program run by the National Committee for Quality Assurance, and are therefore highly relevant to healthcare providers [19]. The proportions of patients achieving each of the targets in the full trial population were prespecified secondary endpoints of the study, and analyses in the patient subgroups were post hoc calculations. IDegLira was associated with a significantly greater proportion of patients achieving all endpoints in all three patient populations (Table 1).

\section{Cost Data}

Costs were estimated from a healthcare payer perspective in the USA. Costs captured in the analysis included the study drug (IDegLira or insulin glargine U100), needles for subcutaneous injection, and self-monitoring of blood glucose (SMBG) testing. No other costs (such as costs of diabetes-related complications) were included in the analyses. Doses of IDegLira and insulin glargine U100 were taken from the DUAL V study at the end of the trial and used to calculate daily costs of treatment with each therapy based on published wholesale acquisition costs $[17,20]$. Costs of SMBG testing were based on an analysis of insurance claims in the USA and were inflated using the consumer price index for medical care [21]. Annual costs were calculated by multiplying the daily cost by 365.25 .

\section{Evaluation of Cost-Effectiveness}

The cost per patient achieving target (cost of control) was assessed for eight endpoints: HbA1c $\leq 6.5 \%$, HbA1c $\leq 6.5 \%$ without confirmed hypoglycemia, HbA1c $\leq 6.5 \%$ without weight gain, HbA1c $\leq 6.5 \%$ without confirmed hypoglycemia and weight gain, $\mathrm{HbA1c}<7 \%$, HbA1c $<7 \%$ without confirmed hypoglycemia, HbA1c $<7 \%$ without weight gain, and HbA1c $<7 \%$ without confirmed hypoglycemia and weight gain. These endpoints were prespecified in the trial protocol. Outcomes were assessed for all endpoints in three patient populations: all patients included in DUAL $\mathrm{V}$, patients with HbA1c $>8.0 \%$ at baseline, and patients with HbA1c $>9.0 \%$ at baseline.

Cost of control was calculated in an economic model developed in Microsoft Excel. The model calculated the cost per patient achieving each target with the two interventions by dividing the annual cost of treatment by the proportion of patients achieving the target. The spending required with insulin glargine U100 to bring one patient to target relative to $\$ 1$ spent on IDegLira was calculated by dividing the cost of control with insulin glargine U100 by the cost of control with IDegLira. An example calculation for the cost per patient achieving a treatment target of HbA1c $<7 \%$ without confirmed hypoglycemia and weight gain in the full DUAL $V$ trial population is shown in Table 2. The analysis was performed over a 
Table 1 Percentage of patients achieving treatment targets

\begin{tabular}{|c|c|c|c|}
\hline & $\begin{array}{l}\text { IDegLira } \\
(\%)\end{array}$ & $\begin{array}{l}\text { Insulin glargine } \\
\text { U100 (\%) }\end{array}$ & $P$ value \\
\hline \multicolumn{4}{|c|}{ Full DUAL V trial population (IDegLira $n=278$, insulin glargine U100 $n=279$ ) } \\
\hline HbAlc $\leq 6.5 \%$ & 55.4 & 30.8 & $<0.0001$ \\
\hline HbAlc $\leq 6.5 \%$ without confirmed hypoglycemia & 41.4 & 19.0 & $<0.0001$ \\
\hline HbAlc $\leq 6.5 \%$ without weight gain & 41.7 & 12.5 & $<0.0001$ \\
\hline HbAlc $\leq 6.5 \%$ without confirmed hypoglycemia and weight gain & 31.7 & 7.5 & $<0.0001$ \\
\hline HbAlc $<7.0 \%$ & 71.6 & 47.0 & $<0.0001$ \\
\hline HbAlc $<7.0 \%$ without confirmed hypoglycemia & 54.3 & 29.4 & $<0.0001$ \\
\hline HbAlc $<7.0 \%$ without weight gain & 50.0 & 19.7 & $<0.0001$ \\
\hline HbAlc $<7.0 \%$ without confirmed hypoglycemia and weight gain & 38.8 & 12.2 & $<0.0001$ \\
\hline \multicolumn{4}{|c|}{ Patients with HbAlc $>8.0 \%$ at baseline ${ }^{\mathrm{b}}$ (IDegLira $n=168$, insulin glargine U100 $n=155$ ) } \\
\hline HbAlc $\leq 6.5 \%$ & 48.8 & 20.0 & $<0.0001$ \\
\hline HbAlc $\leq 6.5 \%$ without confirmed hypoglycemia & 37.5 & 12.3 & $<0.0001$ \\
\hline HbAlc $\leq 6.5 \%$ without weight gain & 35.7 & 5.8 & $<0.0001$ \\
\hline HbAlc $\leq 6.5 \%$ without confirmed hypoglycemia and weight gain & 27.4 & 3.2 & $<0.0001$ \\
\hline HbAlc $<7.0 \%$ & 64.3 & 34.2 & $<0.0001$ \\
\hline HbAlc $<7.0 \%$ without confirmed hypoglycemia & 50.6 & 20.0 & $<0.0001$ \\
\hline HbAlc $<7.0 \%$ without weight gain & 44.0 & 11.0 & $<0.0001$ \\
\hline HbAlc $<7.0 \%$ without confirmed hypoglycemia and weight gain & 35.1 & 6.5 & $<0.0001$ \\
\hline \multicolumn{4}{|c|}{ Patients with HbAlc $>9.0 \%$ at baseline $\mathrm{b}^{\mathrm{b}}$ (IDegLira $n=71$, insulin glargine U100 $n=52$ ) } \\
\hline HbAlc $\leq 6.5 \%$ & 38.0 & 13.5 & 0.0052 \\
\hline HbAlc $\leq 6.5 \%$ without confirmed hypoglycemia & 26.8 & 5.8 & 0.0087 \\
\hline HbAlc $\leq 6.5 \%$ without weight gain & 25.4 & 0.0 & Not defined ${ }^{\mathrm{a}}$ \\
\hline HbAlc $\leq 6.5 \%$ without confirmed hypoglycemia and weight gain & 18.3 & 0.0 & Not defined ${ }^{\mathrm{a}}$ \\
\hline HbAlc $<7.0 \%$ & 56.3 & 23.1 & 0.0006 \\
\hline HbAlc $<7.0 \%$ without confirmed hypoglycemia & 42.3 & 11.5 & 0.0013 \\
\hline HbAlc $<7.0 \%$ without weight gain & 33.8 & 1.9 & 0.0026 \\
\hline HbAlc $<7.0 \%$ without confirmed hypoglycemia and weight gain & 26.8 & 1.9 & 0.0077 \\
\hline
\end{tabular}

Statistical significance was assessed at the 95\% confidence level

HbAlc glycated hemoglobin

a No patients in the insulin glargine U100 arm achieved the treatment target and therefore a $p$ value could not be defined

b Post hoc analysis 
Table 2 Example cost of control calculation for a treatment target of HbAlc $<7 \%$ without confirmed hypoglycemia and weight gain in the full DUAL $V$ trial population

\begin{tabular}{|c|c|c|c|}
\hline & IDegLira & Insulin glargine U 100 & Interpretation \\
\hline Annual drug cost $(\$)$ & 10,280 & 6734 & \\
\hline Drug cost index & $10,280 / 6734=1.5$ & $6734 / 6734=1.0$ & $\begin{array}{l}\text { IDegLira is } 50 \% \text { more costly than insulin } \\
\text { glargine U100 on an annual per patient } \\
\text { basis }\end{array}$ \\
\hline $\begin{array}{l}\text { Drug efficacy ( } \% \text { of } \\
\text { patients achieving } \\
\text { control) }\end{array}$ & 38.8 & 12.2 & \\
\hline Drug efficacy index & $38.8 / 12.2=3.2$ & $12.2 / 12.2=1.0$ & $\begin{array}{l}\text { IDegLira is over } 3 \text { times more effective in } \\
\text { terms of bringing patients to target versus } \\
\text { insulin glargine U100 }\end{array}$ \\
\hline $\begin{array}{l}\text { Cost per patient } \\
\text { achieving control }(\$)\end{array}$ & $\begin{array}{l}10,280 / \\
38.8 \times 100=36,495\end{array}$ & $\begin{array}{l}6734 / \\
12.2 \times 100=55,193\end{array}$ & \\
\hline Cost of control index & $36,495 / 55,193=0.5$ & $55,193 / 55,193=1.0$ & $\begin{array}{l}\text { IDegLira costs approximately half of the } \\
\text { amount of insulin glargine U100 to } \\
\text { achieve a similar outcome }\end{array}$ \\
\hline $\begin{array}{l}\text { Amount spent to achieve } \\
\text { target relative to } \$ 1 \\
\text { spent on IDegLira }\end{array}$ & $36,495 / 36,495=1.0$ & $55,193 / 36,495=2.08$ & $\begin{array}{l}\text { For every } \$ 1 \text { spent on IDegLira, } \$ 2.08 \\
\text { must be spent on insulin glargine U100 } \\
\text { to bring } 1 \text { patient to control }\end{array}$ \\
\hline
\end{tabular}

\$, 2015 US dollars

1-year time horizon, and therefore no discounting was applied. A 1-year time horizon was chosen as it represents a highly relevant period to a healthcare payer. The present analysis is intended to complement conventional long-term analyses, and a long-term analysis based on DUAL V will be published separately.

\section{Compliance with Ethics}

This article does not contain any new studies with human or animal subjects performed by any of the authors.

\section{RESULTS}

\section{Annual Cost Outcomes}

Annual treatment costs were higher for patients receiving IDegLira than for patients receiving insulin glargine U100 because of the higher acquisition costs of IDegLira (Table 3). The annual cost difference was smaller when patients with $\mathrm{HbA} 1 \mathrm{c}>8.0 \%$ at baseline and HbA1c $>9.0 \%$ at baseline were considered. This was a result of doses being higher in both arms in these subgroups, but increases in insulin glargine U100 doses were larger than increases in IDegLira doses. Needle costs showed only small variation between the two treatment arms in all three patient groups, and costs of SMBG testing were equal.

\section{Number Needed to Treat}

IDegLira was consistently associated with a lower number needed to treat (NNT) to bring one patient to target for all endpoints and in all patient populations included in the analysis (Table 4). Differences were greatest in all three patient populations for multifactorial treatment 
Table 3 Cost outcomes

\section{IDegLira (\$)}

Full DUAL V trial population

Annual cost of IDegLira

Annual cost of insulin glargine U100

Annual cost of needles

Annual cost of SMBG testing

Total annual cost

Patients with $\mathrm{HbAlc}>8.0 \%$ at baseline

Annual cost of IDegLira

Annual cost of insulin glargine U100

Annual cost of needles

Annual cost of SMBG test strips

Total annual cost

Patients with $\mathrm{HbAlc}>9.0 \%$ at baseline

Annual cost of IDegLira

Annual cost of insulin glargine U100

Annual cost of needles

Annual cost of SMBG testing

Total annual cost
9516

- $\quad 5991$

167146

$597 \quad 597$

10,280

6734

9631

$-\quad 6580$

$167 \quad 146$

$597 \quad 597$

$10,395 \quad 7323$

9784

- $\quad 6932$

$167 \quad 146$

$597 \quad 597$

$10,549 \quad 7675$

Columns may not sum exactly due to rounding

\$, 2015 US dollars

$S M B G$ self-monitoring of blood glucose

targets which included avoidance of confirmed hypoglycemia and weight/or gain, and when subgroups of patients with higher HbA1c values at baseline were considered.

\section{Cost of Control}

In the full DUAL V trial population (Fig. 1), the annual cost per patient achieving a target of HbA1c $\leq 6.5 \%$ was lower with IDegLira than with continued up-titration of insulin glargine U100 $(\$ 18,556$ versus $\$ 21,862)$ but the annual cost per patient achieving target of HbA1c $<7.0 \%$ was equivalent in the two arms $(\$ 14,358$ versus $\$ 14,327)$. However, when confirmed hypo- glycemia and/or no weight gain were included in the targets, IDegLira was associated with a lower annual cost of control for all endpoints. The annual costs per patient achieving targets of HbA1c $\leq 6.5 \%$ without confirmed hypoglycemia, HbA1c $\leq 6.5 \%$ without weight gain, and HbA1c $\leq 6.5 \%$ without confirmed hypoglycemia and weight gain were $\$ 10,608, \$ 29,215$, and $\$ 57,351$ lower with IDegLira than with continued up-titration of insulin glargine U100, respectively. To bring one patient to a target of HbA1c $\leq 6.5 \%$ or HbA1c $\leq 7.0 \%$ without confirmed hypoglycemia and weight gain with continued up-titration of insulin glargine U100 required spending of $\$ 2.77$ or $\$ 2.08$, respectively, for every $\$ 1$ spent on IDegLira. 
Table 4 Number needed to treat to bring one patient to target

\begin{tabular}{|c|c|c|c|}
\hline & IDegLira & $\begin{array}{l}\text { Insulin } \\
\text { glargine U100 }\end{array}$ & $\begin{array}{l}\text { Absolute } \\
\text { difference }\end{array}$ \\
\hline \multicolumn{4}{|l|}{ Full DUAL V population } \\
\hline $\mathrm{HbAlc} \leq 6.5 \%$ & 1.8 & 3.2 & -1.4 \\
\hline HbAlc $\leq 6.5 \%$ without confirmed hypoglycemia & 2.4 & 5.3 & -2.8 \\
\hline HbAlc $\leq 6.5 \%$ without weight gain & 2.4 & 8.0 & -5.6 \\
\hline $\begin{array}{l}\text { HbAlc } \leq 6.5 \% \text { without confirmed } \\
\text { hypoglycemia and weight gain }\end{array}$ & 3.2 & 13.3 & -10.2 \\
\hline $\mathrm{HbAlc}<7.0 \%$ & 1.4 & 2.1 & -0.7 \\
\hline HbAlc $<7.0 \%$ without confirmed hypoglycemia & 1.8 & 3.4 & -1.6 \\
\hline HbAlc $<7.0 \%$ without weight gain & 2.0 & 5.1 & -3.1 \\
\hline $\begin{array}{l}\text { HbAlc }<7.0 \% \text { without confirmed } \\
\text { hypoglycemia and weight gain }\end{array}$ & 2.6 & 8.2 & -5.6 \\
\hline \multicolumn{4}{|l|}{ Patients with $\mathrm{HbAlc}>8.0 \%$ at baseline $\mathrm{b}^{\mathrm{b}}$} \\
\hline $\mathrm{HbAlc} \leq 6.5 \%$ & 2.0 & 5.0 & -3.0 \\
\hline HbAlc $\leq 6.5 \%$ without confirmed hypoglycemia & 2.7 & 8.1 & -5.5 \\
\hline HbAlc $\leq 6.5 \%$ without weight gain & 2.8 & 17.2 & -14.4 \\
\hline $\begin{array}{l}\text { HbAlc } \leq 6.5 \% \text { without confirmed hypoglycemia } \\
\text { and weight gain }\end{array}$ & 3.6 & 31.3 & -27.6 \\
\hline $\mathrm{HbAlc}<7.0 \%$ & 1.6 & 2.9 & -1.4 \\
\hline HbAlc $<7.0 \%$ without confirmed hypoglycemia & 2.0 & 5.0 & -3.0 \\
\hline \multicolumn{4}{|l|}{ Patients with $\mathrm{HbAlc}>9.0 \%$ at baseline ${ }^{\mathrm{b}}$} \\
\hline $\mathrm{HbAlc} \leq 6.5 \%$ & 2.6 & 7.4 & -4.8 \\
\hline HbAlc $\leq 6.5 \%$ without confirmed hypoglycemia & 3.7 & 17.2 & -13.5 \\
\hline HbAlc $\leq 6.5 \%$ without weight gain & 3.9 & Cannot be calculated $^{a}$ & Cannot be calculated ${ }^{\mathrm{a}}$ \\
\hline $\begin{array}{l}\text { HbAlc } \leq 6.5 \% \text { without confirmed } \\
\text { hypoglycemia and weight gain }\end{array}$ & 5.5 & Cannot be calculated ${ }^{a}$ & Cannot be calculated ${ }^{a}$ \\
\hline $\mathrm{HbAlc}<7.0 \%$ & 1.8 & 4.3 & -2.6 \\
\hline HbAlc $<7.0 \%$ without confirmed hypoglycemia & 2.4 & 8.7 & -6.3 \\
\hline HbAlc $<7.0 \%$ without weight gain & 3.0 & 52.6 & -49.7 \\
\hline $\begin{array}{l}\text { HbAlc }<7.0 \% \text { without confirmed } \\
\text { hypoglycemia and weight gain }\end{array}$ & 3.7 & 52.6 & -48.9 \\
\hline
\end{tabular}

Rows may not sum exactly due to rounding

HbAlc glycated hemoglobin

a Number needed to treat values cannot be calculated as no patients in the insulin glargine U100 arm achieved the treatment target

b Post hoc analysis 


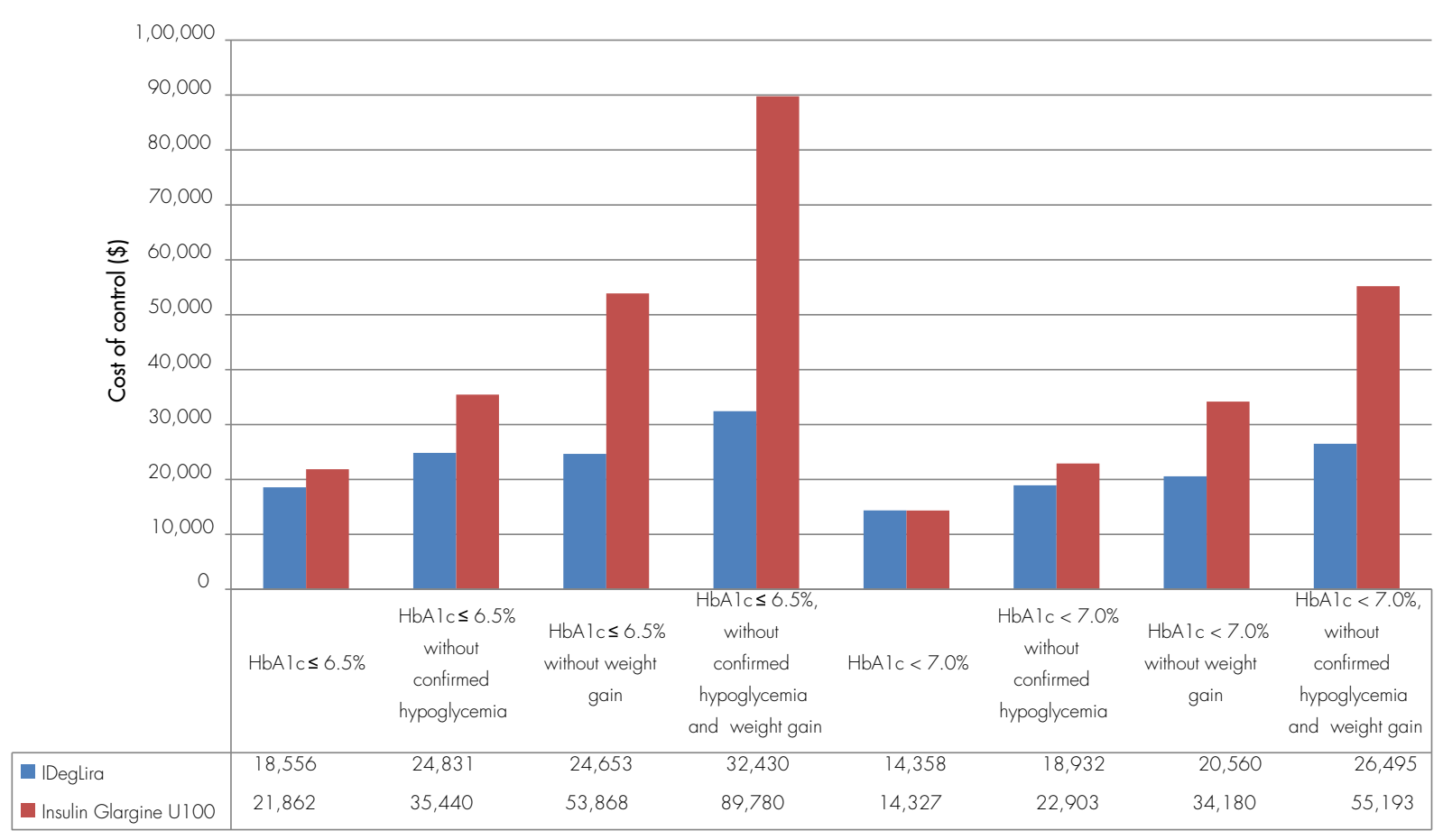

Fig. 1 Cost of control: full DUAL V population. \$, 2015 US dollars; HbAlc, glycated hemoglobin

Cost of control values were higher for all treatment targets in both treatment arms in patients with $\mathrm{HbA} 1 \mathrm{c}>8.0 \%$ at baseline than in the full DUAL $\mathrm{V}$ trial population (Fig. 2). IDegLira was associated with a lower cost per patient achieving control for all treatment targets, both when only HbA1c was considered and for multifactorial targets. Differences between the treatment arms were largest when avoidance of weight gain and confirmed hypoglycemia were captured in the analysis. Bringing one patient to a target of HbA1c $<7.0 \%$ without confirmed hypoglycemia and weight gain required annual spending of $\$ 29,616$ with IDegLira and $\$ 112,663$ with continued up-titration of insulin glargine U100, a difference of $\$ 83,047$ per year.

When patients with $\mathrm{HbA1c}>9.0 \%$ at baseline were considered, IDegLira was associated with a lower cost per patient achieving glycemic targets of $\mathrm{HbA} 1 \mathrm{c} \leq 6.5 \%$ and $\mathrm{HbA} 1 \mathrm{c}<7.0 \%$ (Fig. 3). To bring one patient to HbA1c $\leq 6.5 \%$ or $\mathrm{HbA} 1 \mathrm{c}<7.0 \%$ with continued up-titration of insulin glargine U100 required spending of $\$ 2.05$ and $\$ 1.77$, respectively, for $\$ 1$ spent on IDegLira. IDegLira was also associated with lower costs of control values when multifactorial treatment targets were considered. No patients in the continued up-titration of insulin glargine U100 arm achieved the targets of HbA1c $\leq 6.5 \%$ without confirmed hypoglycemia and weight gain or $\mathrm{HbA} 1 \mathrm{c} \leq 6.5 \%$ without confirmed hypoglycemia and weight gain, with costs of control for IDegLira of $\$ 41,530$ and $\$ 57,642$, respectively, for these targets. The annual cost per patient achieving targets of HbA1c $<7.0 \%$ with no confirmed hypoglycemia, HbA1c $<7.0 \%$ with no weight gain, and $\mathrm{HbA} 1 \mathrm{c}<7.0 \%$ with no weight gain and no confirmed hypoglycemia were $\$ 41,799$, $\$ 372,723$, and $\$ 364,571$ lower with IDegLira than with continued up-titration of insulin glargine U100, respectively.

\section{DISCUSSION}

On the basis of data from the DUAL V trial, IDegLira is more efficacious than up titration of insulin glargine U100 in terms of bringing patients to treatment targets, both HbA1c-focused and multifactorial. While IDegLira was 


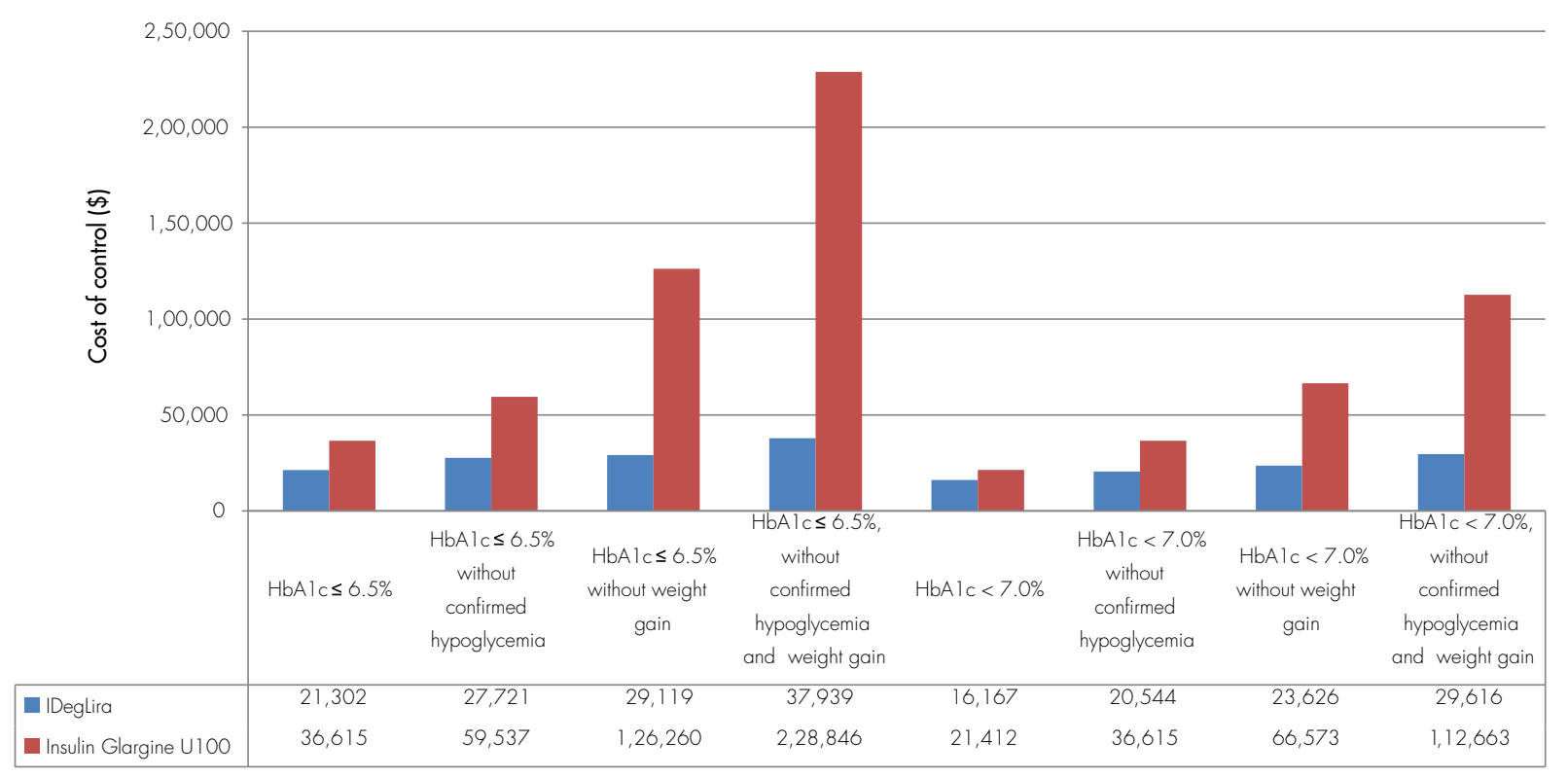

Fig. 2 Cost of control: patients with HbAlc $>8.0 \%$ at baseline. \$, 2015 US dollars; HbAlc, glycated hemoglobin

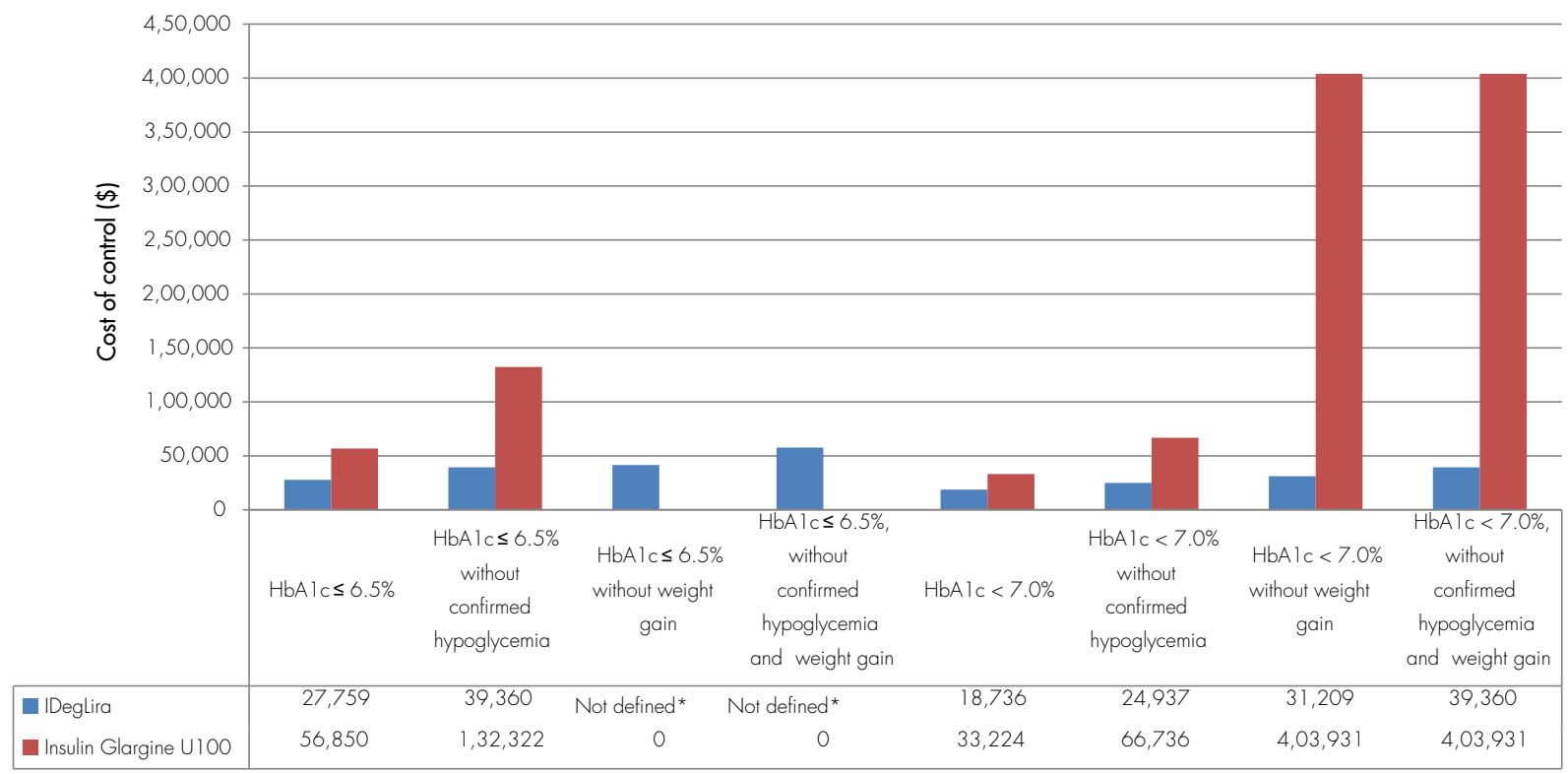

Fig. 3 Cost of control: patients with $\mathrm{HbAlc}>9.0 \%$ at baseline. \$, 2015 US dollars; HbA1c, glycated hemoglobin. ${ }^{*}$ Cost of control values cannot be calculated in the insulin glargine $\mathrm{U} 100$ arm for $\mathrm{HbAlc} \leq 6.5 \%$ without weight gain

associated with increased treatment costs, the cost of control was lower than continued up-titration of insulin glargine U100 for the majority of endpoints included in the analysis. and $\mathrm{HbAlc} \leq 6.5 \%$ without confirmed hypoglycemia and weight gain, as no patients in the insulin glargine U100 arm achieved these treatment targets

Differences in the cost of control values were greatest when treatment targets including hypoglycemia and/or weight gain were considered. This reflects the wide-ranging benefits of 
treatment with IDegLira, targeting not only glycemic control but other risk factors which may reduce the long-term risk of diabetes-related complications and associated costs.

IDegLira also showed significantly greater efficacy and lower cost of control in patients with higher HbA1c values at baseline. This was particularly notable in patients with HbA1c $>9.0 \%$ at baseline, where no patients achieved the treatment targets with continued up-titration of insulin glargine U100 for the composite endpoints of $\mathrm{HbA} 1 \mathrm{c} \leq 6.5 \%$ without weight gain and $\mathrm{HbA} 1 \mathrm{c} \leq 6.5 \%$ without confirmed hypoglycemia and weight gain. This may be a particularly important characteristic of treatment with IDegLira, with the ability to bring patients with poor glycemic control to recommended treatment targets [12-14]. This could allow care to improve across a wide range of patients with T2DM and increase the proportion of patients achieving recognized quality control measures at a lower cost than with alternative interventions. The treatment characteristics of IDegLira, using the complementary mechanisms of action of a basal insulin and a GLP-1 receptor agonist in a single once-daily injection, result in the ability to achieve glycemic control whilst mitigating the risk of hypoglycemia and weight gain, and this improved efficacy offsets increased treatment costs to result in a lower cost of control.

An advantage of the present analysis is the ability to assess the short-term cost-effectiveness of IDegLira versus continued up-titration of insulin glargine $\mathrm{U} 100$ in a simple and transparent manner. Therefore the analysis can be easily replicated and updated when acquisition costs of interventions change or when new clinical data (such as new clinical trials, meta-analyses, or additional post hoc analyses) become available. The analysis does not use long-term projections of clinical and cost outcomes, as are often used in assessments of cost-effectiveness of interventions for T2DM [22]. As a result of the absence of long-term data, such analyses require assumptions around changes in risk factors over time (such as HbA1c, systolic blood pressure, serum lipids, and body weight) and durability of treatment. Furthermore, there may be uncertainty around risk equations used to predict how changes in surrogate outcomes affect the likelihood of end-stage complications [23]. As a result, such analyses are often complex and may be difficult for some audiences to interpret. The analyses described above used an alternative approach, assessing the cost per patient achieving treatment targets based on guidelines released by the American Diabetes Association [12-14]. Analyses using a similar approach to the present analysis have been previously conducted and published in the USA and Canada [24-26].

One of the key limitations of the analysis is that it does not offer a willingness to pay context, as the questions of how much a healthcare payer is willing to pay per patient achieving control is an open one. Therefore it is not possible to generalize across analyses or therapeutic areas, which is a key advantage of the more conventional approach to cost-effectiveness analysis in which the cost per quality-adjusted life year (QALY) gained is calculated. As such, the approach described is not intended to replace conventional, long-term modeling, but provide complementary information to assist decision-makers with a more short-term horizon.

A further limitation of the analysis may be that acute complications, other than hypoglycemia, were not captured in the clinical responder endpoints. In the DUAL $\mathrm{V}$ study, patients receiving IDegLira were at an increased risk of nausea $(9.4 \%$ versus $1.1 \%)$, diarrhea (7.2\% versus $2.5 \%)$, and vomiting (5.0\% versus $1.8 \%)$, compared with patients receiving insulin glargine U100. These acute events may affect adherence to medications and therefore both clinical effectiveness and costs may be altered. Further post hoc analysis may allow these adverse events to be captured in additional composite endpoints and therefore to be reflected in the cost of control calculations. The most frequent adverse event in the DUAL V trial was hypoglycemia. The cost of hypoglycemia was not included in the present analysis, as the higher rate in the insulin glargine U100 arm would have resulted in a greater increase in costs with insulin glargine U100 compared with 
IDegLira. This conservative assumption was chosen to avoid biasing the analysis in favor of IDegLira.

In addition, not all possible treatments a patient not achieving glycemic control on basal insulin may receive have been included in the present analysis. Other treatment intensification options include basal-bolus insulin and addition of liraglutide [14]. To date, there is no direct head-to-head trial evidence comparing IDegLira with these treatment options, although the DUAL VII study comparing IDegLira with basal-bolus insulin will report in mid-2017.

The study also assumes $100 \%$ adherence to all medications included in the analysis, and this has the potential to lead to an overestimation of pharmacy costs and therefore costs of control. In the absence of real-life data on adherence for IDegLira and insulin glargine U100, and the unknown impact of non-adherence on clinical outcomes, it would have been very difficult to incorporate adherence into this analysis. A final limitation may be the use of wholesale acquisition costs. This may also have led to an overestimate of cost of control values, as potential contracting and rebate structures between the healthcare plans and manufacturers were not captured.

\section{CONCLUSIONS}

The present analysis assessed the short-term cost-effectiveness of IDegLira versus continued up-titration of insulin glargine U100 in patients failing to achieve glycemic targets on basal insulin alone. The greater clinical efficacy in terms of bringing patients to treatment targets identified in the DUAL V study results in lower cost of control values for IDegLira versus continued up-titration of insulin glargine U100 from a healthcare payer perspective in the USA. Cost-effectiveness benefits were largest when treatment targets including hypoglycemia and/ or weight gain and patients with higher HbA1c levels were considered. These findings suggest that IDegLira is a cost-effective treatment option versus continued up-titration of insulin glargine U100 in the USA.

\section{ACKNOWLEDGEMENTS}

The present cost-effectiveness analysis was supported by funding from Novo Nordisk $A / S$ and Novo Nordisk Inc. The article processing charges and Open Access fee for this publication were funded by Novo Nordisk A/S and Novo Nordisk Inc. All named authors meet the International Committee of Medical Journal Editors (ICMJE) criteria for authorship for this manuscript, take responsibility for the integrity of the work as a whole, and have given final approval for the version to be published.

Disclosures. Barnaby Hunt and William Valentine are employees of Ossian Health Economics and Communications, which received consulting fees from Novo Nordisk A/S and Novo Nordisk Inc. to support preparation of the analysis. Michelle Mocarski is an employee of Novo Nordisk Inc. Jakob Langer is an employee and shareholder of Novo Nordisk A/S.

Compliance with Ethics Guidelines. This article does not contain any new studies with human or animal subjects performed by any of the authors.

Data Availability. Data sharing is not applicable to this article as no datasets were generated or analyzed during the current study.

Open Access. This article is distributed under the terms of the Creative Commons Attribution-NonCommercial 4.0 International License (http://creativecommons.org/licenses/ by-nc/4.0/), which permits any noncommercial use, distribution, and reproduction in any medium, provided you give appropriate credit to the original author(s) and the source, provide a link to the Creative Commons license, and indicate if changes were made.

\section{REFERENCES}

1. American Diabetes Association. Economic costs of diabetes in the $U$. in 2012. Diabetes Care. 2013;36:1033-46. 
2. Zhuo X, Zhang P, Hoerger TJ. Lifetime direct medical costs of treating type 2 diabetes and diabetic complications. Am J Prev Med. 2013;45(3):253-61.

3. UK Prospective Diabetes Study (UKPDS) Group. Intensive blood-glucose control with sulphonylureas or insulin compared with conventional treatment and risk of complications in patients with type 2 diabetes (UKPDS 33). Lancet. 1998;352:837-53.

4. Holman RR, Paul SK, Bethel MA, Matthews DR, Neil HA. 10-year follow-up of intensive glucose control in type 2 diabetes. N Engl J Med. 2008;359:1577-89.

5. Ismail-Beigi F, Craven T, Banerji MA, et al. Effect of intensive treatment of hyperglycaemia on microvascular outcomes in type 2 diabetes: an analysis of the ACCORD randomised trial. Lancet. 2010;376:419-30.

6. Patel A, MacMahon S, Chalmers J, et al. Intensive blood glucose control and vascular outcomes in patients with type 2 diabetes. $\mathrm{N}$ Engl J Med. 2008;358:2560-72.

7. Duckworth W, Abraira C, Moritz T, et al. Glucose control and vascular complications in veterans with type 2 diabetes. N Engl J Med. 2009;360:129-39.

8. Stettler C, Allemann S, Jüni P, et al. Glycemic control and macrovascular disease in types 1 and 2 diabetes mellitus: meta-analysis of randomized trials. Am Heart J. 2006;152(1):27-38.

9. Turnbull FM, Abraira C, Anderson RJ, et al. Intensive glucose control and macrovascular outcomes in type 2 diabetes. Diabetologia. 2009;52(11):2288-98.

10. Gaede P, Vedel P, Larsen N, Jensen GV, Parving HH, Pedersen O. Multifactorial intervention and cardiovascular disease in patients with type 2 diabetes. N Engl J Med. 2003;348(5):383-93.

11. Gaede P, Lund-Andersen $\mathrm{H}$, Parving $\mathrm{HH}$, Pedersen O. Effect of a multifactorial intervention on mortality in type 2 diabetes. $\mathrm{N}$ Engl J Med. 2008;358(6):580-91.

12. American Diabetes Association. 5. Glycemic targets. Diabetes Care. 2016;39:S39-46.

13. American Diabetes Association. 6. Obesity management for the treatment of type 2 diabetes. Diabetes Care. 2016;39:S47-51.

14. American Diabetes Association. 7. Approaches to glycemic treatment. Diabetes Care. 2016;39:S52-9.
15. Russell-Jones D, Khan R. Insulin-associated weight gain in diabetes-causes, effects and coping strategies. Diabetes Obes Metab. 2007;9(6):799-812.

16. Nathan DM. Clinical practice. Initial management of glycemia in type 2 diabetes mellitus. N Engl J Med. 2002;347(17):1342-9.

17. Lingvay I, Manghi FP, García-Hernández P, et al. Effect of insulin glargine up-titration vs insulin degludec/liraglutide on glycated hemoglobin levels in patients with uncontrolled type 2 diabetes: the DUAL $V$ randomized clinical trial. JAMA. 2016;315(9):898-907.

18. Langer J, Tian Y, Weng W, Gamble C, Mocarski M. Assessing unmet needs for type 2 diabetes patients treated with basal insulin in the United States. Endocr Pract. 2016;22(S2):78-9.

19. National Committee for Quality Assurance. Diabetes Care. https://www.ncqa.org/Portals/0/ Programs/Recognition/DRP_web.pdf. Accessed 16 Dec 2016.

20. Medi-Span Price Rx. http://www.wolterskluwercdi. com/price-rx/. Accessed 16 Dec 2016.

21. Yeaw J, Lee WC, Aagren M, Christensen T. Cost of self-monitoring of blood glucose in the United States among patients on an insulin regimen for diabetes. J Manag Care Pharm. 2012;18(1):21-32.

22. Tarride JE, Hopkins R, Blackhouse G, et al. A review of methods used in long-term cost-effectiveness models of diabetes mellitus treatment. Pharmacoeconomics. 2010;28(4):255-77.

23. American Diabetes Association Consensus Panel. Guidelines for computer modeling of diabetes and its complications. Diabetes Care. 2004;27(9):2262-5.

24. Langer J, Hunt B, Valentine WJ. Evaluating the short-term cost-effectiveness of liraglutide versus sitagliptin in patients with type 2 diabetes failing metformin monotherapy in the United States. J Manag Care Pharm. 2013;19(3):237-46.

25. Lopez JM, Macomson B, Ektare V, Patel D, Botteman M. Evaluating drug cost per response with SGLT2 inhibitors in patients with type 2 diabetes mellitus. Am Health Drug Benefits. 2015;8(6):309-18.

26. Skovgaard R, Jon Ploug U, Hunt B, Valentine WJ. Evaluating the cost of bringing people with type 2 diabetes mellitus to multiple targets of treatment in Canada. Clin Ther. 2015;37(8):1677-88. 